\title{
Histopathological Changes in Placenta of Rat Induced by Levtricetam
}

\author{
Huda Abdulwadood Omer*1, Muna Anwer Kutb² and Huda Abdulla Kaatabi ${ }^{3}$ \\ ${ }^{1}$ Faculty of Medicine and Health Sciences, Forensic Medicine and Toxicology, Al-Mansorrha, Aden, Yemen \\ ${ }^{2}$ Histopathologist, Morphological department, Faculty of Medicine, Aden University, Yemen
}

${ }^{3}$ Physiological Department, Faculty of Medicine, Aden University, Yemen

\begin{abstract}
Background and objectives: Levetiracetam (LEV) is an established second-generation antiepileptic drug. Its use in women with epilepsy of child-bearing potential is a delicate balance between seizure control and adverse effects to the fetus. This study has been designed to evaluate the histopathological effect of levetiracetam in different doses (Therapeutic dose $\& 1 / 4$ LD50), on the placenta of experimental rats.
\end{abstract}

Design and Setting: This study is a randomized single blind control trail conducted from January 2009-December2009.Materials and Methods: Placentas were collected for microscopic examination on day 20 of gestation after rat's scarification.

Results: The placenta showed neither significant reduction in weight nor any overt anomaly compared to control group. Histological examination of the treated groups showed structural changes mainly in the dose of 1/4 LD50. Decidual necrosis, decrease trophospongium area, fibrinoid deposit, necrosis of labyrinth, vascular congestion and hemorrhage were observed. The results suggested that levetiracetam induced dose dependent changes in the structure of placenta.

Conclusions: Therefore, levetiracetam in therapeutic dose can be used safely during pregnancy. However, its safety showed be established in a large scale randomized study with long term follow-up.

Keywords: Placenta; Decidua; Levetiracetam; Histopathological effect

\section{Introduction}

Pregnancy may be associated with increased seizure frequency in close to $20 \%$ of women with epilepsy [1]. The cause of the escalation in seizure frequency during pregnancy is likely multifactorial and may be related, in part, to a change in antiepileptic drug (AED) clearance and serum concentration [2]. Epilepsy has been associated with poor obstetric outcomes that may be the result of the epilepsy or a direct effect of anti-epileptic drugs on placentation [3].

The potential teratogenic effects are major concern for all women with epilepsy that are of childbearing potential. Unlike many other medications, AEDs treatment generally cannot be withdrawn even when pregnancy is planned, since uncontrolled seizures may be harmful to mother as well as to the fetus [4].

Levetiracetam (LEV) (Keppra ${ }^{\circ}$, E Keppra ${ }^{\circ}$ ) is an established secondgeneration antiepileptic drug. Worldwide, levetiracetam is approved as adjunctive treatment of partial onset seizures with or without secondary generalization, and adjunctive treatment of myoclonic seizures associated with juvenile myoclonic epilepsy and primary generalized tonic-clonic (GTC) seizures associated with idiopathic generalized epilepsy [5].

Levetiracetam is a water soluble pyrrolidone derivative [(S)-a-ethyl2-oxo-pyrrolidine acetamide], with a chemical structure that differs from other AEDs. It has a novel structure and unique mechanisms of action. Unlike other AEDs, the mechanisms of action of levetiracetam appear to involve neuronal binding to synaptic vesicle protein $2 \mathrm{~A}$, inhibiting calcium release from intraneuronal stores, opposing the activity of negative modulators of GABA- and glycine-gated currents and inhibiting excessive synchronized activity between neurons. In addition, levetiracetam inhibits $\mathrm{N}$-type calcium channels [6].

Levetiracetam is associated with rapid and complete absorption, high oral bioavailability, minimal metabolism that consists of hydrolysis of the acetamide group, and primarily renal elimination [5].
It is broad spectrum anticonvulsant drug with highly beneficial pharmacokinetic properties, a favorable long- term retention rate and a high responder rate, indicating that it is efficient therapeutic option for the treatment of several types of epilepsy [7].

Levtiracetam and its major metabolite in human, don not induce major structural malformations in developing mice embryos and suggest that they provide a margin of reproductive safety for pregnant epileptic population when compared with other AEDs tested in this mouse models [8].

The risks of seizures and antiepileptic drug (AED) teratogenicity must be balanced when treating pregnant women with epilepsy. Lamotrigine and levetiracetam carried low risks of malformations, and topiramate exhibited a dose-dependent risk. Levetiracetam controlled seizures more effectively than lamotrigine and topiramate [9].

Nowadays, It Is becoming increasingly used in women with epilepsy of childbearing potential and thus also during pregnancy [1012 ], although it is known that levetiracetam during pregnancy cross the placenta and attains pharmacologically active concentration in the fetus [11].

The placenta is a temporary and crucial organ for proper fetal development. It is enables communication between the mother and

*Corresponding author: Huda Abdulwadood Omer, Assistant Professor Faculty of Medicine and Health Sciences, Forensic Medicine and Toxicology, AlMansorrha, Aden, Aden, Al-Mansorrha, Yemen, 00967, Tel: 00967735992571, Fax: 00967737581059; E-mail: hudafreedom@yahoo.com

Received October 19, 2014; Accepted November 25, 2014; Published December 03, 2014

Citation: Omer HA, Kutb MA, Kaatabi HA (2014) Histopathological Changes in Placenta of Rat Induced by Levtricetam. Int $\mathrm{J}$ Neurorehabilitation 1: 134. doi:10.4172/2376-0281.1000134

Copyright: $\odot 2014$ Omer HA, et al. This is an open-access article distributed under the terms of the Creative Commons Attribution License, which permits unrestricted use, distribution, and reproduction in any medium, provided the original author and source are credited. 
her fetus. During the pregnancy, it acts as a substitute lung, digestive tract and kidney for the fetus; it also provides endocrine and immunity functions that are necessary for the maintenance of a successful pregnancy [13-15].

It is known that nearly all drugs cross the placenta at least to some extent [16] currently there is very little information concerning the pharmacokinetics of this drug in the feto-placental unit, and the changes induced by the drug in the placenta are not reported. The major goal of this study is to determine the effect of levetiracetam (at therapeutic dose and $1 /{ }_{4} \mathrm{LD}_{50}$ ) on rat placenta.

\section{Material and Methods}

A group of white albino (male and female) rats with mean weight 180 (60.0 grams), brought from Assuit University animal house were included in the study. They were kept in environmentally controlled rooms (temperature of $28-32^{\circ} \mathrm{C}$, humidity $40-60 \%$, noise free environment and with 12 hours light-dark cycle). The females and the males were placed separately in different capacious cages and allowed to pair over night. On the following morning notification of vaginal plug was regarded as Day zero of gestation (GD0). All the rats had access to water and animal diet ad libitum [17].

Sixty female rats being pregnant were included in the study and classified into three groups:

Control Group: consisted of 20 pregnant females supplied with oral normal saline.

Group I: consisted of 20 pregnant females supplied with oral therapeutic dose of levetiracetam (54mg/day) [18], in two divided doses per day.

Group II: consisted of 20 pregnant females supplied with high dose oral levetiracetam $\left({ }^{1} /{ }_{4} \mathrm{LD}_{50}=70 \mathrm{mg} / \mathrm{Kg}\right.$ body weight $)$ [19], in two divided doses per day.

Levetiracetam was given in its already prepared formulation (Tiratam) oral solution $100 \mathrm{mg} / \mathrm{ml}$ from Al-Andalous for pharmaceuticals-Egypt Industries. In all groups drugs were administered by gastric tube from $6^{\text {th }}$ day up to the $19^{\text {th }}$ day of gestation. Each rat dam was killed by cervical spine dislocation on the day 20 of gestation in order to avoid premature birth.

The gravid uterine horns were exposed by lower midline abdominal incision. The fetuses and the placenta were examined in situ. Each placenta was carefully examined. They were then removed and preserved in $10 \%$ buffered neutral formalin. They were dehydrated and embedded in paraffin. Serial sections $6 \mu \mathrm{m}$ thick were cut and stained with hematoxylin and eosin. Observations were made by examining the serial sections under a light microscope. Statistics of the individual data were analyzed by using Fisher exact test and level of significance was set at $\mathrm{P}$ - value $<0.05$.

\section{Results}

Placenta is an organ with circulation from both the mother and the fetus. Rat placenta has two zones 1) junction zone, which is composed of outer giant cells that separated exteriorly located maternal deciduas basalis and inner trophospongium which consist of highly packed basophilic spongioblast cells 2) labyrinth zone, which is composed of communicated network of the maternal lacuna and embryonic capillaries [20]. The materno-embryonic nutritional and gaseous exchange is believed to take place in the labyrinth [21].
Gross placental examination in both study groups (I and II) showed neither significant reduction in weight nor gross anomalies as compared to the control group.

Light microscopic examination in the placentas of group I ( $54 \mathrm{mg} /$ day), showed similar architecture to that of control group (No statistically significant difference). Lesser degrees (small areas) of placental changes are seen in Group I. The structural changes in placentas of group II were more prominent and severe. The results revealed dose-dependent pathological changes in the placenta. These structural changes are found in 1) deciduas basalis site 2) trophoblastic zone and 3) labyrinth.

This study revealed that sections which were obtained from study group II showed multiple lesions that include decidual necrosis (Figures 1-5) $(p=0.00001)$ and fibrin deposition (Figures 6 and 7) in decidual site and labyrinth zone $(p=0.002)$. The thickness of placental barrier increased (Figure 7). The fetal blood vessels were mostly hyalinized (Figure 8); this was primarily due to increased amount of fibrinoid material. Trophoblastic giant cells and spongiotrophoblasts were decreased in number after administration of levetiracetam, (Figures $1-4)$ which was predominantly in group II $(p=0.048)$. Some of the giant cells had cytoplasmic vacuoles, presumably phagosomes, and pyknotic nucleus (Figures 2 and 9).

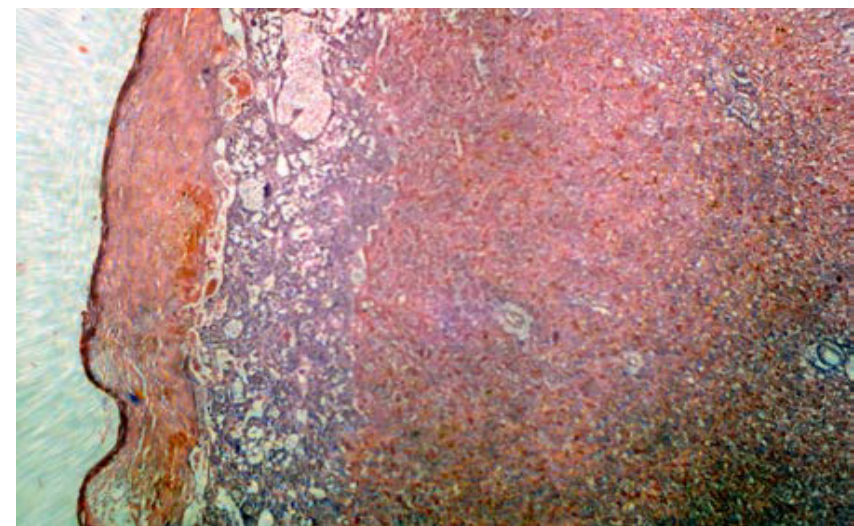

Figure 1: Placenta of experimental group II, Showing decidual necrosis and the area of trophoblast cells and spongiotrophoblast are decreased in number due to cytolysis of glycogen cells \& trophoblasts.

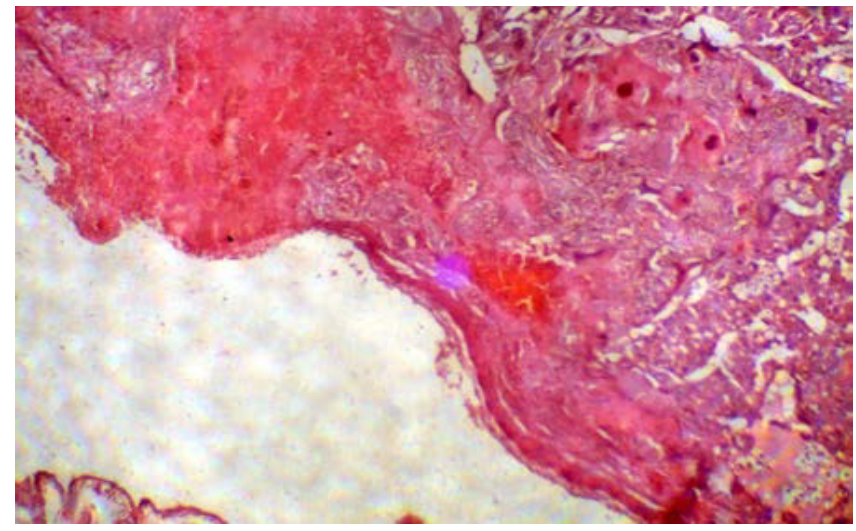

Figure 2: Placenta of experimental group II, showing extensive decidual necrosis and hemorrhage. A nucleus of spongiotrophoblast seems pyknotic in LEV treated group II. 
Citation: Omer HA, Kutb MA, Kaatabi HA (2014) Histopathological Changes in Placenta of Rat Induced by Levtricetam. Int J Neurorehabilitation 1: 134. doi:10.4172/2376-0281.1000134

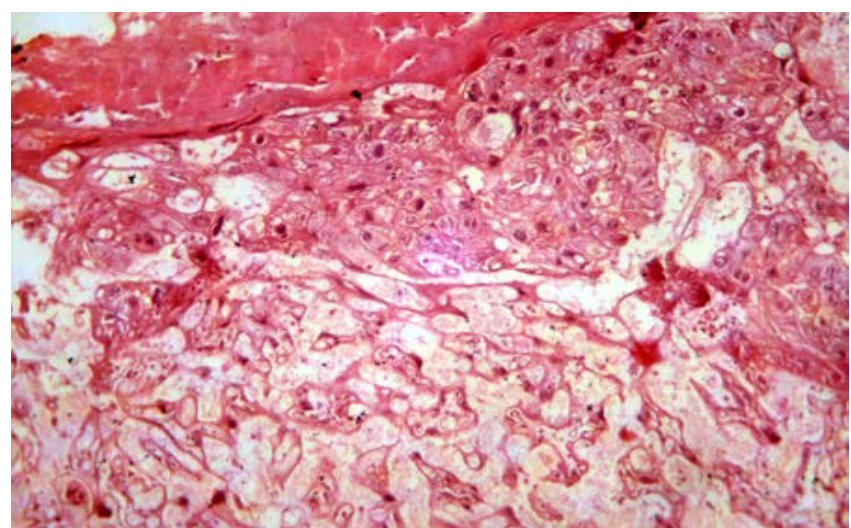

Figure 3: Placenta of experimental group II, Showing decidual necrosis and the area of trophospongium zone have been decreased in number and a nucleus of spongiotrophoblast seems pyknotic. Histological changes in labyrinth area showed decreased cellular strands septa had lost their cellular architecture which act as a barrier that separates the maternal blood from embryonic capillaries; resulting in admixing of maternal and fetal blood and decreased vessels formation.

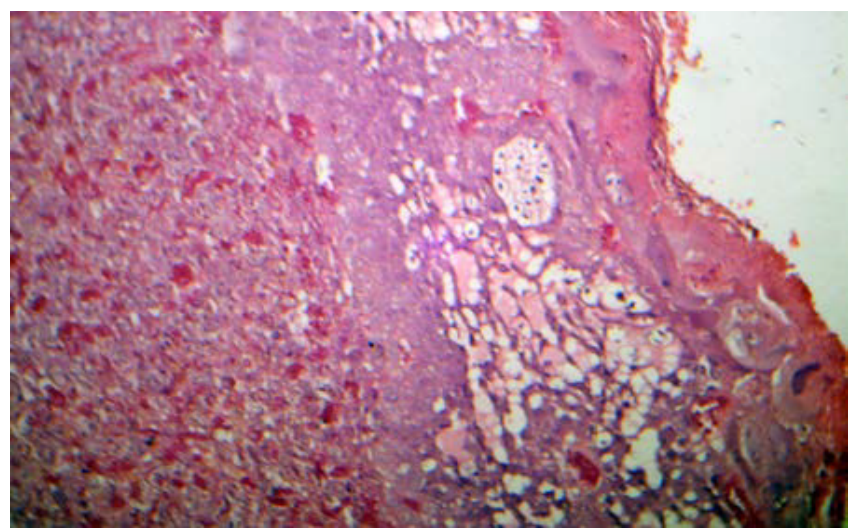

Figure 4: Placenta of experimental group II showing decidual necrosis, cytolysis of glycogen cells \& trophoblast lysis in trophospongium zone.

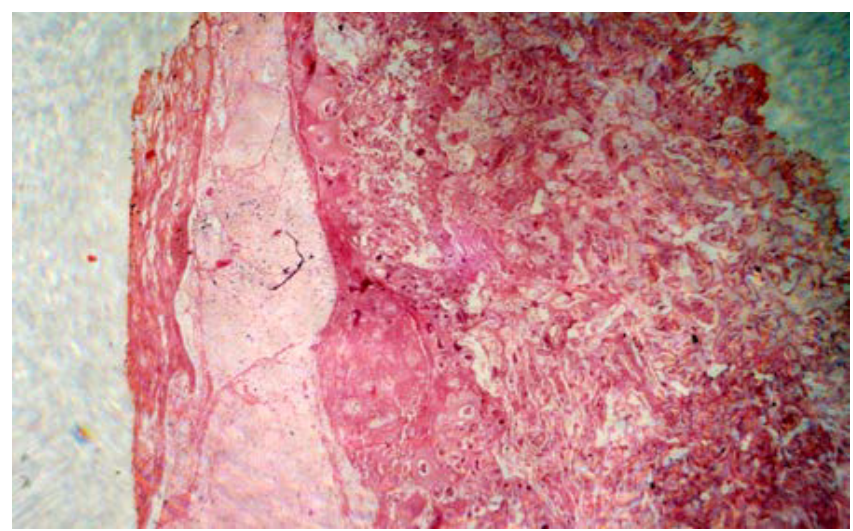

Figure 5: Group II placenta showing extensive necrosis in all layers and hemorrhage in labyrinth.

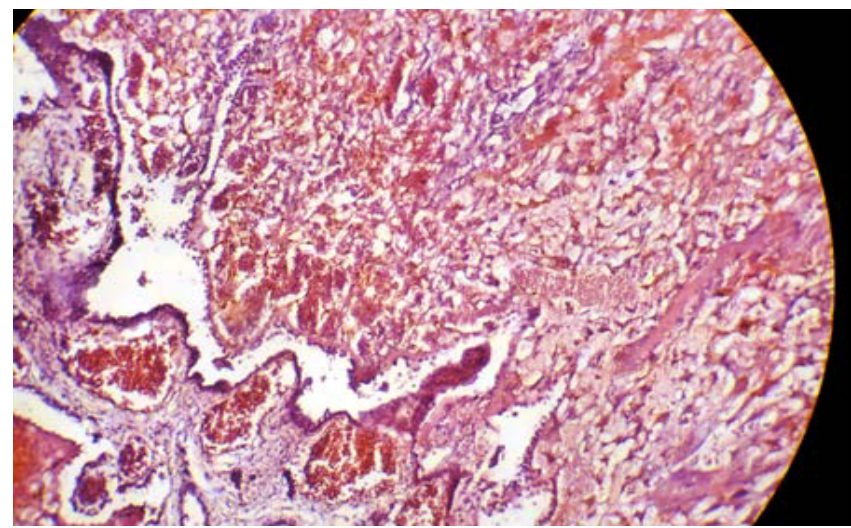

Figure 6: Placenta of experimental group II showing reduction in thickness of trophoblastic septa and irregular dilatation of maternal sinusoids with deposition of fibrin. Defect in the placental barrier due to destruction of trophoblast cell and reduced the thickness of septa.

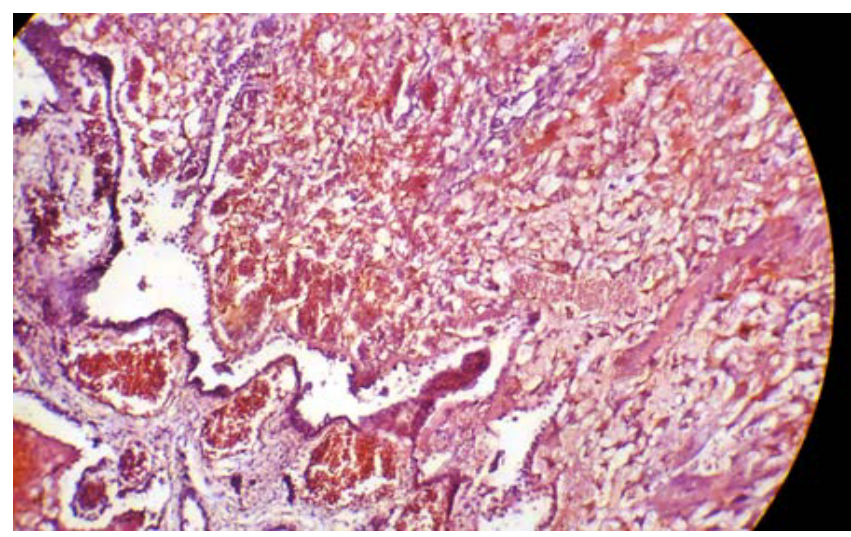

Figure 7: Group II placenta showing congestion of blood vessels, decrease trophoblast in numbers, poorly define placental barrier resulting in admixing of maternal and fetal blood and showing increase fibrinoid deposition.

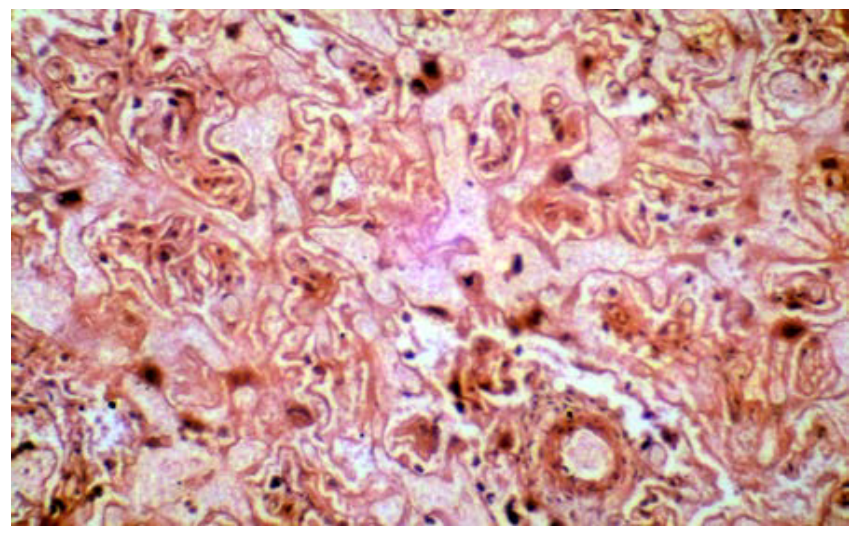

Figure 8: Labyrinth zone of group II placenta showing poorly forming blood vessels and irregular dilatation of maternal blood vessels, Decreased the number of trophoblast cells, hyalinized blood vessels. 
Citation: Omer HA, Kutb MA, Kaatabi HA (2014) Histopathological Changes in Placenta of Rat Induced by Levtricetam. Int J Neurorehabilitation 1: 134. doi:10.4172/2376-0281.1000134

Page 4 of 6

In the labyrinth the trophoblasts showed necrotic foci $(\mathrm{p}=0.048)$ and disintegration of the barrier that separates the maternal blood from embryonic capillaries, resulting in admixing of maternal and fetal blood (Figures 7 and 8). Furthermore, vascular congestion (Figures 10 and 11) $(\mathrm{p}=0.001)$ and extensive areas of hemorrhage (Figures 5 and 10) $(\mathrm{p}=0.00001)$ were observed in labyrinth.

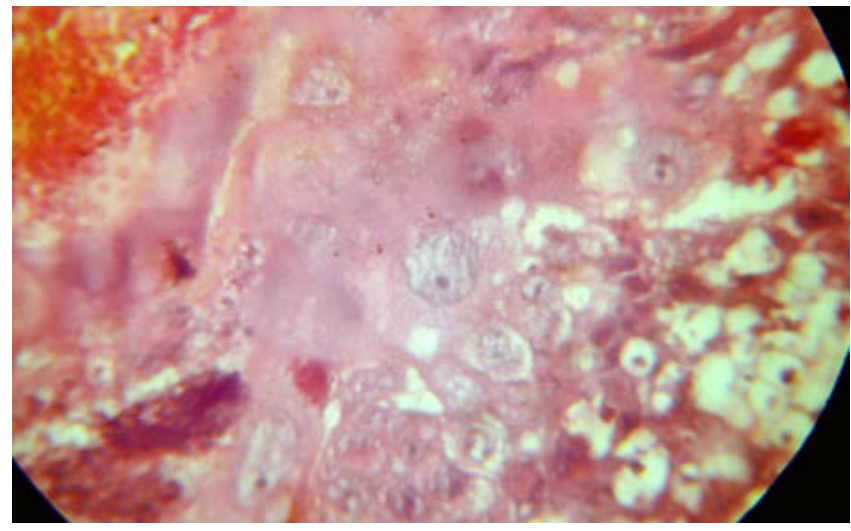

Figure 9: Placenta of experimental group II showing apoptosis \& decreased number of trophoblast cells.

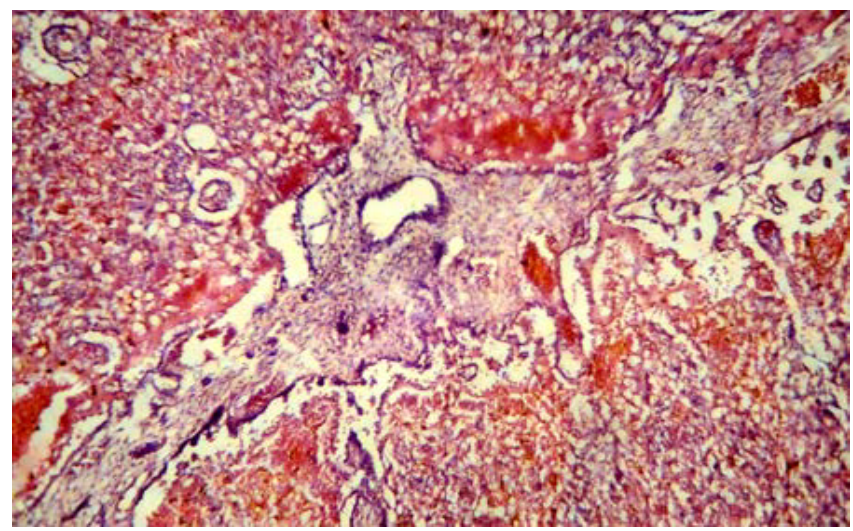

Figure 10: Group II placenta showing congestion and hemorrhage.

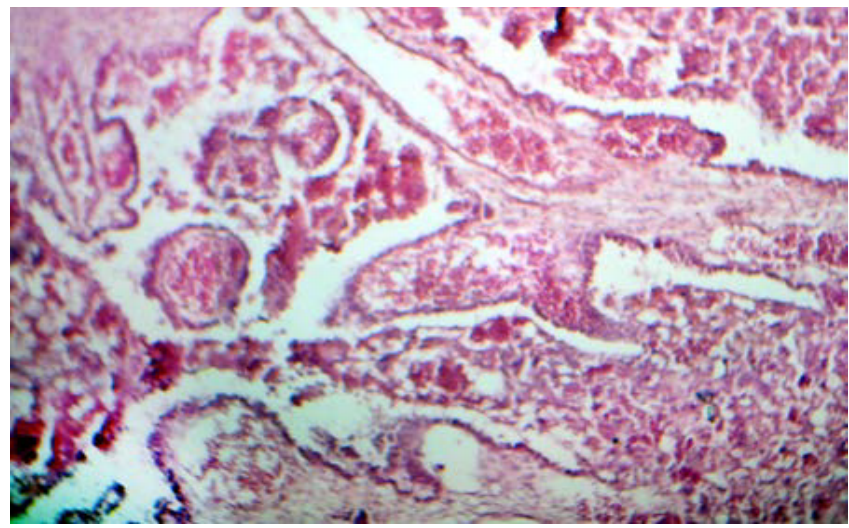

Figure 11: Group II placenta showing severe congestion.

\section{Discussion}

The placenta not only provides a link between the circulation of two distinct individuals (maternal and fetal) but also acts as a barrier to protect the fetus from xenobiotics in the maternal blood [22].

The present results revealed dose-dependent pathological changes in the placenta. This is manifested as severe structural changes in rats that received the higher dose (group II), thus, may lead to reduced uteroplacental blood flow which appear to be associated with increased risk of poor outcome (the outcome cannot be predicted but must be empirically determined).

Our study showed that levetiracetam causes necrosis at the maternal deciduas which may occur due to deficiency in the maternal vascular circulation. These results are similar to the deficient vascular development described in the homozygous gene knockout models in which deletion of the entire adrenomedullin (Adm) gene responsible for potent, endogenous vasodilator peptide in the germ line produced embryos with little vascularization in the yolk sac and thin umbilical cords and the few fully formed vessels were revealed to be "leaky" on angiography (Table 1) [23-26].

Trophospongium zone was decreased which resulted from degeneration of trophoblasts. Trophoblast giant cells (TGCs) were present that had an increased number of vacuoles. This finding is in agreement with other studies which suggest that levetiracetam might causes cell degeneration and death; thus giant cells act as biological elimination of degenerated trophoblasts and finally cause diminished of trophoblast cells (Table 2) $[25,27,28]$.

Our study also illustrated necrotic foci of trophoblasts in the labyrinth. The labyrinth septa had lost their architecture, with fibrin deposition and decreased vessels formation. These changes are might be due to modulation of nutritional and homeostatic conditions in which the embryo depends on in its development and may influence its viability and growth. Fibrin deposition inhibits maternal perfusion of the placenta, which then causes placental necrosis that is often associated with fetal morbidity and mortality (Table 3) [29].

\begin{tabular}{|l|c|c|c|c|c|c|}
\hline \multirow{2}{*}{$\begin{array}{l}\text { Placental } \\
\text { findings }\end{array}$} & \multicolumn{4}{|c|}{ Decidual Necrosis } & \multicolumn{2}{c|}{ Total } \\
\cline { 2 - 7 } & \multicolumn{2}{|c|}{ Present } & \multicolumn{2}{c|}{ Absent } & \multicolumn{2}{c|}{} \\
\cline { 2 - 7 } & NO & $\%$ & NO & $\%$ & NO & $\%$ \\
\hline Control group(20) & 0 & 0.0 & 20 & 100.0 & 20 & 100.0 \\
\hline Group I (20) & 2 & 10.0 & 18 & 90.0 & 20 & 100.0 \\
\hline Group II (20) & 12 & 60.0 & 8 & 40.0 & 20 & 100.0 \\
\hline Total & 14 & 23.3 & 46 & 76.7 & 60 & 100.0 \\
\hline
\end{tabular}

p: 0.00001 statistically highly significant

Table 1: Comparison of histoplathological effect of LEV in placenta (Maternal deciduas) of study Groups.

\begin{tabular}{|l|c|c|c|c|c|c|}
\hline \multirow{2}{*}{ Placental findings } & \multicolumn{3}{|c|}{ Decrease Trophospongium Zone } & \multicolumn{2}{c|}{ total } \\
\cline { 2 - 7 } & \multicolumn{2}{|c|}{ Present } & \multicolumn{2}{c|}{ Absent } & \multicolumn{2}{c|}{} \\
\cline { 2 - 7 } & NO & $\%$ & NO & $\%$ & NO & $\%$ \\
\hline Control group(20) & 2 & 10.0 & 18 & 90.0 & 20 & 100.0 \\
\hline Group I (20) & 6 & 30.0 & 14 & 70.0 & 20 & 100.0 \\
\hline Group II (20) & 9 & 45.0 & 11 & 55.0 & 20 & 100.0 \\
\hline Total & 17 & 28.3 & 43 & 71.7 & 60 & 100.0 \\
\hline
\end{tabular}

p: 0.048 statistically significant

Table 2: Comparison of histoplathological effect of LEV in placenta (Trophospongium Zone) of study groups. 
Citation: Omer HA, Kutb MA, Kaatabi HA (2014) Histopathological Changes in Placenta of Rat Induced by Levtricetam. Int J Neurorehabilitation 1:

\begin{tabular}{|l|c|c|c|c|c|c|}
\hline \multirow{2}{*}{ Placental findings } & \multicolumn{3}{|l|}{ Fibrinoid Deposition } & \multicolumn{2}{|c|}{ Total } \\
\cline { 2 - 7 } & NO Present & $\%$ & NO & $\%$ & NO & $\%$ \\
\hline Control group(20) & 3 & 15.0 & 17 & 85.0 & 20 & 100.0 \\
\hline Group I (20) & 2 & 10.0 & 18 & 90.0 & 20 & 100.0 \\
\hline Group II (20) & 11 & 55.0 & 9 & 45.0 & 20 & 100.0 \\
\hline \multicolumn{1}{|c|}{ Total } & 16 & 26.7 & 44 & 73.3 & 60 & 100.0 \\
\hline
\end{tabular}

p: 0.002 statistically highly significant

Table 3: Comparison of histoplathological effect of LEV in placenta (Fibrinoid deposition) of the study groups.

Khera [30] showed that valporic acid caused placental necrosis which may interfere with growth of the embryo. Ozer et al. [31] found that macroscopic evaluation of placenta from chick embryos treated with LEV within the therapeutic range at $50 \mathrm{mg} / \mathrm{kg}$ caused immaturity of the placental vessel network manifested as a decrease in their number and width in the study group in comparison to the controls. They concluded that LEV delays the closure of the neural tube and microcephaly. It also further disturbs morphological, biochemical, and functional development. The necrosis in the labyrinth is secondary to the deficient vascular development in the placenta and decreased utero/ placental/fetal oxygenation [32]. Wu et al. [33] reported that fibrin deposition in the anticonvulsant topiramate may be due to inhibition of placental cartinine transporter. Furthermore, congestion of maternal vascular lacunae in the labyrinth was observed, they were broken following degeneration of the trophoblasts and formed extensive areas of hemorrhage [34]. These findings were similar to that found in the results of Khera [30] and Mathew et al. [35] (Tables 4-6).

\begin{tabular}{|l|c|c|c|c|c|c|}
\hline \multirow{2}{*}{ Placental findings } & \multicolumn{4}{|c|}{ Necrosis of Labyrinth } & \multicolumn{3}{|c|}{ Total } \\
\cline { 2 - 7 } & \multicolumn{2}{|c|}{ Present } & \multicolumn{2}{|c|}{ Absent } & \multicolumn{2}{c|}{} \\
\cline { 2 - 7 } & NO & $\%$ & NO & $\%$ & NO & $\%$ \\
\hline Control group(20) & 2 & 10.0 & 18 & 90.0 & 20 & 100.0 \\
\hline Group I (20) & 6 & 30.0 & 14 & 70.0 & 20 & 100.0 \\
\hline Group II (20) & 9 & 45.0 & 11 & 55.0 & 20 & 100.0 \\
\hline \multicolumn{1}{|c|}{ Total } & 17 & 28.3 & 43 & 71.7 & 60 & 100.0 \\
\hline
\end{tabular}

$p: 0.048$ statistically significant

Table 4: Comparison of histoplathological effect of LEV in placenta (Necrosis of Labyrinth) of the study groups.

\begin{tabular}{|l|c|c|c|c|c|c|}
\hline \multirow{2}{*}{ Placental findings } & \multicolumn{3}{|c|}{ Vascular Congestion } & \multicolumn{2}{|c|}{ Total } \\
\cline { 2 - 7 } & \multicolumn{2}{|c|}{ Present } & \multicolumn{2}{c|}{ Absent } & \multicolumn{2}{c|}{} \\
\cline { 2 - 7 } & NO & $\%$ & NO & $\%$ & NO & $\%$ \\
\hline Control group(20) & 4 & 20.0 & 16 & 80.0 & 20 & 100.0 \\
\hline Group I (20) & 3 & 15.0 & 17 & 85.0 & 20 & 100.0 \\
\hline Group II (20) & 13 & 65.0 & 7 & 35.0 & 20 & 100.0 \\
\hline \multicolumn{1}{|c|}{ Total } & 20 & 33.3 & 40 & 66.7 & 60 & 100.0 \\
\hline
\end{tabular}

p: 0.001 statistically highly significant

Table 5: Comparison of histoplathological effect of LEV in placenta (Vascular congestion) of the study groups.

\begin{tabular}{|l|c|c|c|c|c|c|}
\hline \multirow{2}{*}{ Placental findings } & \multicolumn{4}{|c|}{ Hemorrhage } & \multicolumn{2}{|c|}{ Total } \\
\cline { 2 - 7 } & \multicolumn{2}{|c|}{ Present } & \multicolumn{2}{|c|}{ Absent } & \multicolumn{2}{c|}{} \\
\cline { 2 - 7 } & NO & $\%$ & NO & $\%$ & NO & $\%$ \\
\hline Control group(20) & 1 & 5.0 & 19 & 95.0 & 20 & 100.0 \\
\hline Group I (20) & 0 & 0.0 & 20 & 100.0 & 20 & 100.0 \\
\hline Group II (20) & 9 & 45.0 & 11 & 55.0 & 20 & 100.0 \\
\hline \multicolumn{1}{|c|}{ Total } & 10 & 1.7 & 50 & 98.3 & 60 & 100.0 \\
\hline
\end{tabular}

$p: 0.00001$ statistically highly significant

Table 6: Comparison of histoplathological effect of LEV in placenta (Hemorrhage) of the study groups.

\section{Conclusion}

Histopathological lesions were detected in the rat placenta treated with a high dose of levetiracetam during the period of organogenesis (the higher doses of LEV induces extensive placental lesions). Our study suggested that LEV at therapeutic dose can be used safely during pregnancy. Further large scale randomized studies with longer followup periods are required to confirm its safety.

\section{References}

1. EURAP Study Group (2006) Seizure control and treatment in pregnancy: observations from the EURAP epilepsy pregnancy registry. Neurology 66: 354360.

2. Abou-Khalil BW (2008) Does increased levetiracetam clearance during pregnancy require planned intervention? Epilepsy Curr 8: 62-63.

3. Kwieciß̊,ska P, WiÅıniewska J, Gregoraszczuk EÅ (2011) Effects of valproic acid (VPA) and levetiracetam (LEV) on proliferation, apoptosis and hormone secretion of the human choriocarcinoma BeWo cell line. Pharmacol Rep 63: 1195-1202.

4. Tomson T, Battino D (2008) Teratogenic effects of antiepileptic drugs. Seizure 17: 166-171.

5. Lyseng-Williamson KA (2011) Levetiracetam: a review of its use in epilepsy. Drugs 71: 489-514.

6. Anuradha S, Pretti K (2013) Levetiracetam with its therapeutic potentials Internaional journal of universal pharmacy and biosciences. 2: 45-55.

7. De Smedt T, Raedt R, Vonck K, Boon P (2007) Levetiracetam: the profile of a noval anticonvulsant drug-part I: preclinical data. CNS Drug Rev. 13: 57-78.

8. Isoherranen N, Spiegelstein $\mathrm{O}$, Bialer M, Zhang J, Merriweather M, et al (2003) Developmental outcome of levetiracetam, its major metabolite in humans, 2-pyrrolidinone N-butyric acid, and its enantiomer (R)-alpha-ethyloxo-pyrrolidine acetamide in a mouse model of teratogenicity. Epilepsia 44: 1280-1288.

9. Meador KJ (2014) Epilepsy: Pregnancy in women with epilepsy-risks and management. Nat Rev Neurol 10: 614-616.

10. Long L (2003) Levetiracetam monotherapy during pregnancy: a case series. Epilepsy Behav 4: 447-448.

11. Tomson T, Palm R, Källén K, Ben-Menachem E, Söderfeldt B, et al. (2007) Pharmacokinetics of levetiracetam during pregnancy, delivery, in the neonatal period, and lactation. Epilepsia 48: 1111-1116.

12. De Smedt T, Raedt R, Vonck K, Boon P (2007) Levetiracetam: part II, the clinical profile of a novel anticonvulsant drug. CNS Drug Rev 13: 57-78.

13. Boyd CA (2013) Review: Epithelial aspects of human placental trophoblast. Placenta 34 Suppl: S24-26.

14. Carter AM (2012) Evolution of placental function in mammals: the molecular basis of gas and nutrient transfer, hormone secretion, and immune responses. Physiol Rev 92: 1543-1576.

15. Malek A (2013) Role of IgG antibodies in association with placental function and immunologic diseases in human pregnancy. Expert Rev Clin Immunol 9: 235-249.

16. Myllynen P, Pienimäki P, Vähäkangas K (2005) Human placental perfusion method in the assessment of transplacental passage of antiepileptic drugs. Toxicol Appl Pharmacol 207: 489-494.

17. Padmanabhan R, Abdulrazzaq YM, Bastaki SM, Shafiullah M, Chandranath SI (2003) Experimental studies on reproductive toxicologic effects of lamotrigine in mice. Birth Defects Res B Dev Reprod Toxicol 68: 428-438.

18. Paget GE, Barnes JM (1964) Toxicological tests in evaluation of drug activities. Edited by: Laurence D.R. Pharmacometrics. New York: Acad. Press. 13: 134135

19. Sugawara T, Kato M, Furuhama K, Inage F, Suzuki N, et al. (1994) Single dose toxicity study of the new cognition-enhancing agent nefiracetam in mice, rats and dogs. Arzneimittelforschung 44: 211-213.

20. Cinquetti R (1983) Histological changes in the chorioallantoic placenta of the mouse with increasing gestational age. Arch Ital Anat Embriol 88: 267-279. 
Citation: Omer HA, Kutb MA, Kaatabi HA (2014) Histopathological Changes in Placenta of Rat Induced by Levtricetam. Int J Neurorehabilitation 1: 134. doi:10.4172/2376-0281.1000134

21. Hernandez-Verdun D (1974) Morphogenesis of the syncytium in the mouse placenta. Ultrastructural study. Cell Tissue Res 148: 381-396.

22. Syme MR, Paxton JW, Keelan JA (2004) Drug transfer and metabolism by the human placenta. Clin Pharmacokinet 43: 487-514.

23. Caron KM, Smithies O (2001) Extreme hydrops fetalis and cardiovascula abnormalities in mice lacking a functional Adrenomedullin gene. Proc Natl Acad Sci U S A 98: 615-619.

24. Hay DL, Smith DM (2001) Knockouts and transgenics confirm the importance of adrenomedullin in the vasculature. Trends Pharmacol Sci 22: 57-59.

25. Ma HY, Li H, Wang JC, Liu XQ, Xu FS, et al. (2006) [Effects of lead exposure to rat placenta and pups during different gestation periods]. Zhonghua Yu Fang Yi Xue Za Zhi 40: 101-104.

26. Mishra A, Singh M (2008) Topiramate induced histopathological changes in placenta of rats. Indian J Exp Biol 46: 715-719.

27. Kosif R, Akta G, Öztekin A (2008) Microscopical examination of placenta of rat prenatally exposed to Aleo barbadensis : A preliminary study. Int. J. Morphol. 26: $275-281$

28. Moreno MR, Fussell KC, Gröters S, Schneider S, Strauss V, et al. (2013) Epoxiconazole-Induced Degeneration in Rat Placenta and the Effects of Estradiol Supplementation. Birth defects research. Part B: Development and reproductive toxicology. 98: 208-221.
29. Roberts DJ (2008) Placental pathology, a survival guide. Arch Pathol Lab Med 132: $641-651$.

30. Khera KS (1992) Valproic acid-induced placental and teratogenic effects in rats. Teratology 45: 603-610.

31. Ozer FD, Demirel A, YÄ \pm Imaz Dilsiz O, AydÄ $\pm n$ M, Ã-zdemir N, et al. (2012) Effects of Levetiracetam on neural tube development and closure of the chick embryos in ovo. Childs Nerv Syst 28: 969-976.

32. Witlin AG, Li ZY, Wimalawansa SJ, Grady JJ, Grafe MR, et al. (2002) Placenta and fetal growth and development in late rat gestation is dependent on adrenomedullin. Biol Reprod 67: 1025-1031.

33. Wu SP, Shyu MK, Liou HH, Gau CS, Lin CJ (2004) Interaction between anticonvulsants and human placental carnitine transporter. Epilepsia 45: 204210

34. Singh R (2005) Placental changes induced by Trichloroacetic acid in rat Journal of the Anatomical Society. 54: 1-9.

35. Mathew M, Garg S, Rai L, Kustogi P (2008) Placental Chorangiosis - A report of two cases with unusual associations and review of literature. The Internet Journal of Gynecology and Obstetrics. 11 